Wright State University

CORE Scholar

$5-1-2003$

\title{
Ga Vacancies as Dominant Intrinsic Acceptors in GaN Grown by Hydride Vapor Phase Epitaxy
}

\author{
J. Oila \\ J. Kivioja \\ V. Ranki \\ K. Saarinen \\ David C. Look \\ Wright State University - Main Campus, david.look@wright.edu
}

See next page for additional authors

Follow this and additional works at: https://corescholar.libraries.wright.edu/physics

Part of the Physics Commons

\section{Repository Citation}

Oila, J., Kivioja, J., Ranki, V., Saarinen, K., Look, D. C., Molnar, R. J., Park, S. S., Lee, S. K., \& Han, J. Y. (2003). Ga Vacancies as Dominant Intrinsic Acceptors in GaN Grown by Hydride Vapor Phase Epitaxy. Applied Physics Letters, 82 (20), 3433-3435.

https://corescholar.libraries.wright.edu/physics/85

This Article is brought to you for free and open access by the Physics at CORE Scholar. It has been accepted for inclusion in Physics Faculty Publications by an authorized administrator of CORE Scholar. For more information, please contact library-corescholar@wright.edu. 


\section{Authors}

J. Oila, J. Kivioja, V. Ranki, K. Saarinen, David C. Look, Richard J. Molnar, S. S. Park, S. K. Lee, and J. Y. Han 


\title{
Ga vacancies as dominant intrinsic acceptors in GaN grown by hydride vapor phase epitaxy
}

\author{
J. Oila, J. Kivioja, V. Ranki, and K. Saarinen ${ }^{\mathrm{a})}$ \\ Laboratory of Physics, Helsinki University of Technology, P.O. Box 1100, FIN-02015 HUT, Finland \\ D. C. Look \\ Semiconductor Research Center, Wright State University, Dayton, Ohio
}

R. J. Molnar

Massachusetts Institute of Technology, Lincoln Laboratory, Lexington, Massachusetts 02420-9108

S. S. Park, S. K. Lee, and J. Y. Han

Samsung Advanced Institute of Technology, P.O. Box 111, Suwon, Korea 440-600

(Received 18 December 2002; accepted 26 February 2003; publisher error corrected 20 May

2003)

\begin{abstract}
Positron annihilation measurements show that negative Ga vacancies are the dominant acceptors in $n$-type gallium nitride grown by hydride vapor phase epitaxy. The concentration of Ga vacancies decreases, from more than $10^{19}$ to below $10^{16} \mathrm{~cm}^{-3}$, as the distance from the interface region increases from 1 to $300 \mu \mathrm{m}$. These concentrations are the same as the total acceptor densities determined in Hall experiments. The depth profile of $\mathrm{O}$ is similar to that of $\mathrm{V}_{\mathrm{Ga}}$, suggesting that the Ga vacancies are complexed with the oxygen impurities. (c) 2003 American Institute of Physics. [DOI: $10.1063 / 1.1569414]$
\end{abstract}

Hydride vapor phase epitaxy (HVPE) is a method for the fast growth of GaN layers on sapphire substrates. The quality of these layers improves drastically with thickness, making them interesting candidates for substrates of $\mathrm{GaN}$ homoepitaxy. For example, the dislocation densities decrease from the very high values of $>10^{11} \mathrm{~cm}^{-2}$ close to GaN/sapphire interface to less than $10^{8} \mathrm{~cm}^{-2}$ in films which are thicker than $50 \mu \mathrm{m} .{ }^{1-4}$ The impurity concentrations, ${ }^{5,6}$ electrical and optical properties, ${ }^{1,5-8}$ and deep level defects ${ }^{2,9}$ have also qualitatively similar depth profiles. The atomic structures of the dominating point defects, however, have not been identified and their role as electrically active centers has not been quantitatively estimated.

Earlier positron annihilation experiments in $\mathrm{GaN}$ have identified the Ga vacancy, ${ }^{10}$ which most likely forms defect complexes with $\mathrm{O}_{\mathrm{N}}$ impurities. ${ }^{11,12}$ These previous works have been performed either in bulk crystals where the impurity concentrations are high or in epitaxial samples with dislocation densities above $10^{9} \mathrm{~cm}^{-2}$. As both negative impurities ${ }^{13}$ and dislocations ${ }^{14}$ are positron traps in $\mathrm{GaN}$, it has not been possible to determine experimentally the charge of $\mathrm{V}_{\mathrm{Ga}}$ complexes or the quantitative role of them in the electrical properties of the material. In this work, we show that negatively charged $\mathrm{Ga}$ vacancies are the dominant acceptor defects in $n$-type HVPE GaN.

The GaN samples were grown by hydride vapor phase epitaxy on sapphire substrates. The layers with thicknesses of $1,5,10-14,36-39$, and $49-68 \mu \mathrm{m}$ were fabricated at MIT Lincoln Laboratory. A free-standing 300- $\mu$ m-thick sample was grown at Samsung Advanced Institute of Technology. It was separated from the sapphire by laser-induced lift-off. The electron concentrations of the $n$-type $\mathrm{GaN}$ layers decrease with thickness from mid $10^{19} \mathrm{~cm}^{-3}$ (1 $\mu \mathrm{m}$ sample)

a)Electronic mail: ksa@fyslab.hut.fi to $10^{6} \mathrm{~cm}^{-3}$ (60 $\mu \mathrm{m}$ sample). In the free-standing $\mathrm{GaN}$ sample the electron concentration is only $5 \times 10^{15} \mathrm{~cm}^{-3}$.

Conventional positron lifetime spectroscopy ${ }^{15}$ was performed in samples thicker than $30 \mu \mathrm{m}$. The positron annihilations in the sapphire substrate were subtracted from the spectra by estimating their fraction $(20 \%-40 \%)$ from the exponential stopping profile of fast positrons from ${ }^{22} \mathrm{Na}$ source. In order to measure depth profiles, all $\mathrm{GaN}$ layers were investigated by implanting $0-25 \mathrm{keV}$ positrons from a monoenergetic beam at the depths of $0-1 \mu \mathrm{m}$ from the surface. The measured Doppler broadening of the $511 \mathrm{keV}$ annihilation radiation was characterized by the low and high electron-momentum parameters $S$ and $W{ }^{15}$

The average positron lifetime $\tau_{\mathrm{av}}$ in the free-standing HVPE GaN sample is indistinguishable from that in the $\mathrm{GaN}$ lattice ( $\tau_{\mathrm{B}}=160 \mathrm{ps}$ ) at $300-500 \mathrm{~K}$ but increases to $162 \mathrm{ps}$ at $30 \mathrm{~K}$ (Fig. 1). The average positron lifetime in the 40-60 $\mu \mathrm{m} \mathrm{GaN}$ layers is larger than in the free-standing $\mathrm{GaN}$. The positron lifetime spectra can be decomposed into two components, corresponding to annihilations in the bulk lattice (lifetime $\tau_{1}$ ) and at vacancy defects (lifetime $\tau_{2}$ ). The lifetime $\tau_{2}=235 \pm 5 \mathrm{ps}$ is the same as identified previously for the positrons annihilating as trapped at $\mathrm{Ga}$ vacancies, ${ }^{10-13}$ indicating that defects involving $\mathrm{V}_{\mathrm{Ga}}$ are present.

The increase of the average positron lifetime at low temperatures shows that the positron trapping rate ${ }^{15}$

$$
\kappa=\mu_{V}\left[\mathrm{~V}_{\mathrm{Ga}}\right]=\frac{1}{\tau_{B}} \frac{\tau_{\mathrm{av}}-\tau_{B}}{\tau_{2}-\tau_{\mathrm{av}}}=\frac{1}{\tau_{B}} \frac{S_{L}-S_{B}}{S_{V}-S_{L}}
$$

increases roughly as $\kappa \propto T^{-1 / 2}$ ( $\mu_{V}$ is the positron trapping coefficient, see later for the definitions of the $S$ parameters). The temperature dependence of the average positron lifetime is totally reversible and reproducible, indicating that the concentration of $\mathrm{Ga}$ vacancies remains constant. Because the Fermi level is close to the conduction band, the charge states 


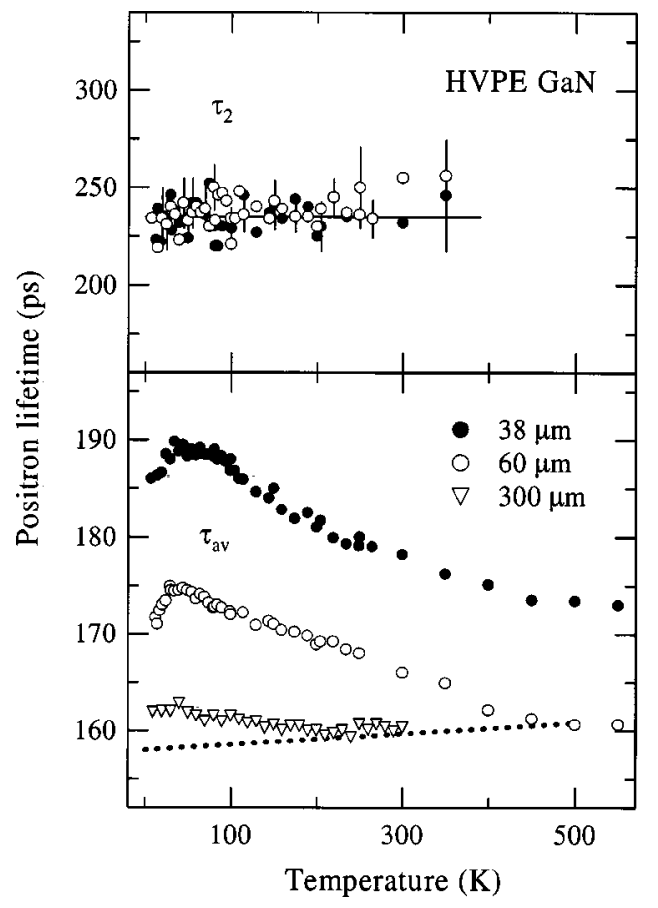

FIG. 1. Average positron lifetime ( $\left.\tau_{\mathrm{av}}\right)$ and the lifetime of positrons trapped at vacancies $\left(\tau_{2}\right)$ vs measurement temperature in $\mathrm{GaN}$ samples with three different thicknesses. The dashed line shows the temperature dependence the positron lifetime in bulk GaN lattice (see Ref. 13).

of acceptor-like defects like $\mathrm{V}_{\mathrm{Ga}}$ do not change with the measurement temperature. The temperature dependence of the positron trapping rate $\kappa \propto T^{-1 / 2}$ thus reflects the increase of the positron trapping coefficient $\mu_{V}$ at low temperatures. This behavior is expected for negative vacancies. ${ }^{15,16}$ When the thermal velocity of positrons decreases, the overlap of the positron wave function with the attractive Coulomb potential becomes more efficient, thus facilitating faster transition into the vacancy. ${ }^{16}$

Thus, the increase of positron trapping at low temperatures gives direct experimental evidence that the charge of Ga vacancies is negative. This is in good agreement with the results of theoretical calculations, ${ }^{17}$ which predict a charge state of 3- for isolated $\mathrm{Ga}$ vacancies and 2-for $\mathrm{V}_{\mathrm{Ga}}-\mathrm{Si}_{\mathrm{Ga}}$ and $\mathrm{V}_{\mathrm{Ga}}-\mathrm{O}_{\mathrm{N}}$ complexes in $n$-type GaN.

The concentrations of Ga vacancies can be estimated from the positron results by applying Eq. (1). We assume a positron trapping coefficient of $\mu_{V}=3 \times 10^{15} \mathrm{~s}^{-1} / N_{\mathrm{at}}\left(N_{\mathrm{at}}\right.$ $=8.775 \times 10^{22} \mathrm{~cm}^{-3}$ is the atomic density of GaN). ${ }^{13,15}$ The Ga vacancy concentrations are $6 \times 10^{16} \mathrm{~cm}^{-3}$ and 2 $\times 10^{16} \mathrm{~cm}^{-3}$ in the 40 - and $60-\mu \mathrm{m}$-thick layers, respectively. By scaling the positron trapping coefficient as $\mu_{V} \propto \kappa_{V}$ $\propto T^{-1 / 2}$, we can estimate the $\mathrm{V}_{\mathrm{Ga}}$ concentration of 2 $\times 10^{15} \mathrm{~cm}^{-3}$ in the free-standing GaN sample.

The positron data show further that the defects involving Ga vacancies are the dominant negatively charged acceptors in the samples. The enhancement of positron trapping at low temperatures would not be observed, if other negative centers competed with $\mathrm{V}_{\mathrm{Ga}}$ as positron traps. For example, negative ions such as $\mathrm{Mg}_{\mathrm{Ga}}^{-}$localize positrons at hydrogenic states at low temperatures, strongly decreasing the fraction of positron annihilations at vacancy defects and consequently the average positron lifetime. ${ }^{13}$ In the present HVPE GaN samples, only a small decrease of $\tau_{\mathrm{av}}$ is detected at $T$

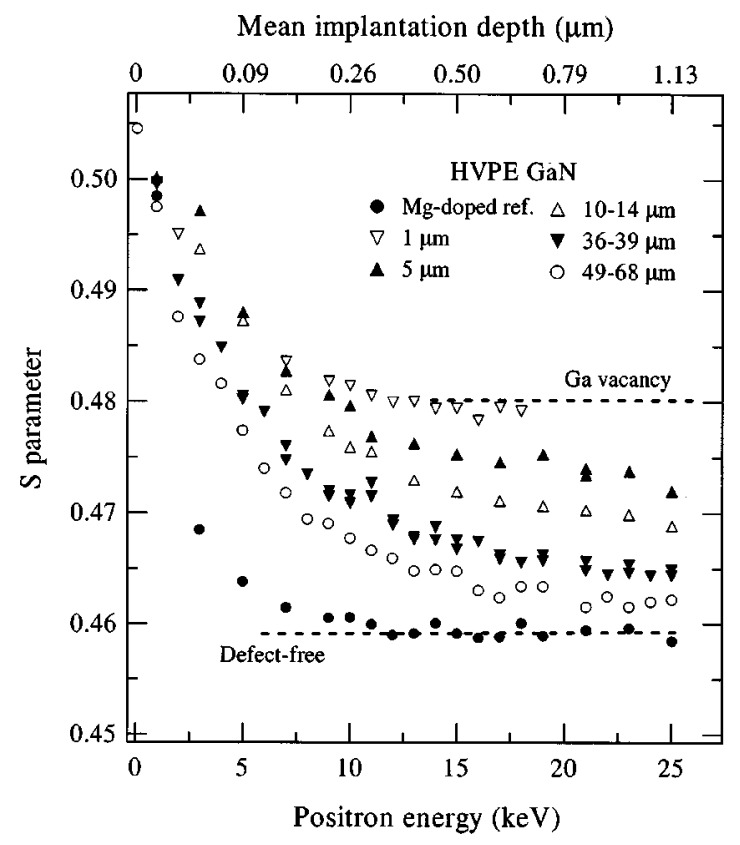

FIG. 2. The low electron-momentum parameter $S$ as a function of the positron implantation energy. The dashed lines show the values of $S$ parameter in defect-free GaN and at the Ga vacancy. The top axis indicates the mean stopping depth corresponding to the positron implantation energy.

$<30 \mathrm{~K}$. In fact, the secondary ion-mass spectrometry in the bulk of the $60-\mu \mathrm{m}$-thick layer has shown that the concentrations of typical acceptor impurities are $[\mathrm{Mg}]<10^{16} \mathrm{~cm}^{-3}$ and $[\mathrm{C}]<10^{15} \mathrm{~cm}^{-3}$, i.e., clearly less than $\left[\mathrm{V}_{\mathrm{Ga}}\right]$.

The temperature-dependent Hall experiments yield the total donor and acceptor concentrations of $N_{D}=8$ $\times 10^{16} \mathrm{~cm}^{-3}$ and $N_{A}=3 \times 10^{16} \mathrm{~cm}^{-3}$ in the $60-\mu \mathrm{m}$-thick GaN on sapphire and $N_{D}=8 \times 10^{15} \mathrm{~cm}^{-3}$ and $N_{A}=3$ $\times 10^{15} \mathrm{~cm}^{-3}$ in the free-standing GaN sample. The total acceptor concentrations are in very good agreement with the concentrations of $\mathrm{Ga}$ vacancies determined in positron experiments, confirming that $\mathrm{Ga}$ vacancies are the dominant acceptors in HVPE GaN.

To detect positron trapping at $\mathrm{Ga}$ vacancies in thinner $(<30 \mu \mathrm{m})$ films we implant positrons from a monoenergetic beam and probe the Doppler broadening of the annihilation radiation (Fig. 2). At low positron implantation energies surface effects with a high characteristic $S$ parameter of $S$ $>0.5$ are observed. With increasing $E$ the positron diffusion to the surface decreases and the $S(E)$ curve saturates to a constant level $S=S_{L}$, characterizing the interior of the layer at about $0.5-1 \mu \mathrm{m}$ below the surface. The $S_{L}$ values are systematically larger than $S_{B}$ recorded in defect free $\mathrm{GaN}$, demonstrating the presence of vacancy defects. The linearity of valence and core electron momentum distributions (i.e., the so-called $S$ vs $W$ plot $)^{15}$ indicates that (i) the samples have a single dominant vacancy-type positron trap and (ii) the momentum distribution of annihilating electrons in this vacancy is similar to that of Ga vacancy detected in thicker $(>30 \mu \mathrm{m})$ films where both positron lifetime and Doppler broadening experiments could be performed. Hence, the Ga vacancy is the dominant positron trap in all layers.

The $\mathrm{V}_{\mathrm{Ga}}$ concentrations can be estimated from the Doppler data by applying Eq. (1). We determine the value $S_{V}$ $=1.046 S_{B}$ for total positron trapping at the Ga vacancy by 


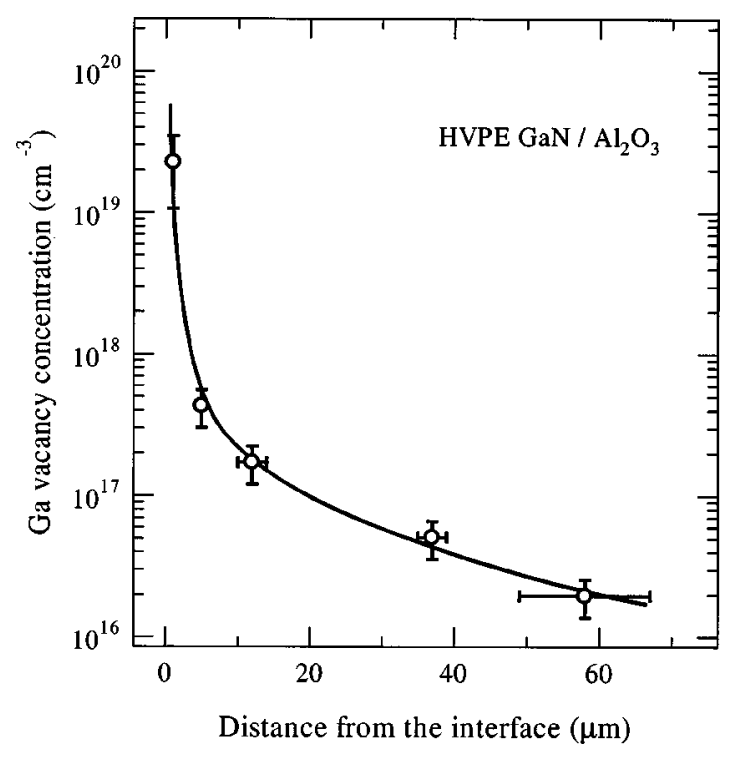

FIG. 3. The concentration of Ga vacancies as a function of the thickness of the $\mathrm{GaN}$ layers on sapphire.

combining positron lifetime and Doppler experiments in the thick layers, similarly as earlier. ${ }^{10}$ Since the growth is reproducible, the estimated $\mathrm{V}_{\mathrm{Ga}}$ concentrations construct a depth profile of $\mathrm{Ga}$ vacancies over the entire thickness of the HVPE GaN layer (Fig. 3). The concentration of Ga vacancies decreases from almost $10^{20} \mathrm{~cm}^{-3}$ close to the GaN/ sapphire interface down to $10^{16} \mathrm{~cm}^{-3}$ at $60 \mu \mathrm{m}$. The $300-$ $\mu \mathrm{m}$-thick free-standing $\mathrm{GaN}$ has even smaller $\left[\mathrm{V}_{\mathrm{Ga}}\right]$ $\approx 10^{15} \mathrm{~cm}^{-3}$ as deduced in positron lifetime experiments.

The depth profile of Ga vacancies in Fig. 3 is very similar to those reported earlier for dislocations, ${ }^{1-4} \mathrm{O}$ impurities, ${ }^{5,6}$ optical properties ${ }^{1,6-8}$ and deep defect levels. ${ }^{2,9}$ All these results manifest the general improvement of the quality of the HVPE GaN material with increasing thickness, but more direct correlations are not obvious. The presence of Ga vacancies in the structure of the dislocation core has been suggested by theoretical calculations. ${ }^{18}$ Close to the interface the $\mathrm{V}_{\mathrm{Ga}}$ concentration is $10^{20} \mathrm{~cm}^{-3}$ and the dislocation density is very high $\left(>10^{11} \mathrm{~cm}^{-2}\right)$. Obviously Ga vacancies exist close to dislocations and even in the core structure as suggested also by the consistent analysis of electrical, transmission electron microscopy, and positron data. ${ }^{5}$

At thicknesses of $>5 \mu \mathrm{m}$ from the interface the dislocation density is $<10^{9} \mathrm{~cm}^{-2}$, which is less than the typical sensitivity limit of positron trapping at dislocations. Positron studies in dislocation-free bulk crystals ${ }^{10}$ and in hetero and homoepitaxial layers ${ }^{11,14}$ have shown that Ga vacancies are formed in $n$-type GaN independently of dislocations, and the dislocations at grain boundaries are free of $\mathrm{V}_{\mathrm{Ga}} \cdot{ }^{14}$ The Ga vacancies observed in HVPE GaN at $>5 \mu \mathrm{m}$ from the interface are thus probably not associated with dislocations, but present simply because their formation energy is low in $n$-type GaN. ${ }^{17}$ According to electron irradiation studies the isolated $\mathrm{V}_{\mathrm{Ga}}$ is mobile already at $600 \mathrm{~K},{ }^{12}$ i.e., at much lower temperatures than applied in the HVPE growth. However, the $\mathrm{Ga}$ vacancies bound to defect complexes such as
$\mathrm{V}_{\mathrm{Ga}}-\mathrm{O}_{\mathrm{N}}$ have a considerably higher thermal stability. ${ }^{12}$ In fact, SIMS experiments ${ }^{5,6}$ show that the $\mathrm{O}$ concentration profile is similar to that of $\mathrm{V}_{\mathrm{Ga}}$ in Fig. 3. This correlation gives further evidence to attribute the observed $\mathrm{Ga}$ vacancies in HVPE GaN to complexes $\mathrm{V}_{\mathrm{Ga}}-\mathrm{O}_{\mathrm{N}}$.

In summary, our positron annihilation experiments show that $\mathrm{Ga}$ vacancies are the dominant acceptors $n$-type $\mathrm{GaN}$ grown by hydride vapor phase epitaxy on sapphire. The concentration of Ga vacancies decreases from almost $10^{20} \mathrm{~cm}^{-3}$ to less than $10^{16} \mathrm{~cm}^{-3}$ when the thickness of the GaN layers increases from 1 to more than $100 \mu \mathrm{m}$. Furthermore, the Ga vacancy concentration is equal to the total acceptor density determined by temperature-dependent Hall experiments. The depth profile of $\mathrm{Ga}$ vacancies is similar to that of $\mathrm{O}$, suggesting that the $\mathrm{Ga}$ vacancies formed during the growth are bound to defect complexes with the oxygen impurities.

This work was supported by the Academy of Finland (DENOS project). The work of D.C.L. was supported under AFOSR Grant No. F49620-00-1-0347 and the Lincoln Laboratory portion by the ONR under Air Force Contract No. F19628-00-C-0002. Opinions, interpretations, conclusions, and recommendations are those of the authors and not necessarily endorsed by the United States Air Force.

${ }^{1}$ L. Chernyak, A. Osinsky, G. Nootz, A. Schulte, J. Jasinski, M. Benamara, Z. Liliental-Weber, D. C. Look, and R. J. Molnar, Appl. Phys. Lett. 77, 2695 (2000).

${ }^{2}$ Z.-Q. Fang, D. C. Look, J. Jasinski, M. Benamara, Z. Liliental-Weber, and R. J. Molnar, Appl. Phys. Lett. 78, 332 (2001).

${ }^{3}$ J. Jasinski, W. Swider, Z. Liliental-Weber, P. Visconti, K. M. Jones, M. A. Reshchikov, F. Yun, H. Morkoc, S. S. Park, and K. Y. Lee, Appl. Phys. Lett. 78, 2297 (2001).

${ }^{4}$ G. Nootz, A. Schulte, L. Chernyak, A. Osinsky, J. Jasinski, M. Benamara, and Z. Liliental-Weber, Appl. Phys. Lett. 80, 1355 (2002).

${ }^{5}$ D. C. Look, C. E. Stutz, R. J. Molnar, K. Saarinen, and Z. Liliental-Weber, Solid State Commun. 117, 571 (2001).

${ }^{6}$ X. L. Sun, S. H. Goss, L. J. Brillson, D. C. Look, and R. J. Molnar, J. Appl. Phys. 91, 6729 (2002).

${ }^{7}$ F. Bertram, S. Srinivasan, F. A. Ponce, T. Riemann, J. Christen, and R. J. Molnar, Appl. Phys. Lett. 78, 1222 (2001).

${ }^{8}$ S. H. Goss, X. L. Sun, A. P. Young, L. J. Brillson, D. C. Look, and R. J. Molnar, Appl. Phys. Lett. 78, 3630 (2001).

${ }^{9}$ A. Y. Polyakov, N. B. Smirnov, A. V. Govorkov, Z.-Q. Fang, D. C. Look, R. J. Molnar, and A. V. Osinsky, J. Appl. Phys. 91, 6580 (2002).

${ }^{10}$ K. Saarinen, T. Laine, S. Kuisma, J. Nissilä, P. Hautojärvi, L. Dobrzynski, J. M. Baranowski, K. Pakula, R. Stepniewski, M. Wojdak, A. Wysmolek, T. Suski, M. Leszczynski, I. Grzegory, and S. Porowski, Phys. Rev. Lett. 79, 3030 (1997).

${ }^{11}$ J. Oila, V. Ranki, K. Saarinen, P. Hautojärvi, J. Likonen, J. M. Baranowski, K. Pakula, M. Leszczynski, and I. Grzegory, Phys. Rev. B 63, 045205 (2001).

${ }^{12}$ K. Saarinen, T. Suski, I. Grzegory, and D. C. Look, Phys. Rev. B 64, 233201 (2001).

${ }^{13}$ K. Saarinen, J. Nissilä, P. Hautojärvi, J. Likonen, T. Suski, I. Grzegory, B. Lucznik, and S. Porowski, Appl. Phys. Lett. 75, 2441 (1999).

${ }^{14}$ J. Oila, K. Saarinen, A. E. Wickenden, D. D. Koleske, R. L. Henry, and M. E. Twigg, Appl. Phys. Lett. 82, 1021 (2003).

${ }^{15}$ K. Saarinen, P. Hautojärvi, and C. Corbel, in Identification of Defects in Semiconductors, edited by M. Stavola (Academic, New York, 1998), p. 209.

${ }^{16}$ M. J. Puska, C. Corbel, and R. M. Nieminen, Phys. Rev. B 41, 9980 (1990).

${ }^{17}$ J. Neugebauer and C. Van de Walle, Appl. Phys. Lett. 69, 503 (1996).

${ }^{18}$ A. F. Wright and U. Grossner, Appl. Phys. Lett. 73, 2751 (1998). 